\title{
MODELING THE SHALLOW SUBSURFACE STRUCTURE IN THE URBAN AREA OF KOCHI CITY
}

\author{
Michihiro OHORI $^{1}$, Seckin CITAK $^{2}$, Takeshi NAKAMURA ${ }^{2}$, Minoru SAKAUE ${ }^{3}$, \\ Shunsuke TAKEMURA ${ }^{3}$, Takashi FURUMURA ${ }^{4}$, Teito TAKEMOTO ${ }^{3}$, \\ Kazuhisa IWAI ${ }^{5}$, Atsuki KUBO ${ }^{6}$, Kazuo KAWATANI ${ }^{6}$, Sawa TAJIMA ${ }^{7}$, \\ Narumi TAKAHASHI ${ }^{2}$ and Yoshiyuki KANEDA ${ }^{8}$ \\ ${ }^{1}$ Member of JAEE, Earthquake and Tsunami Research Project for Disaster Prevention, \\ Japan Agency for Marine-Earth Science and Technology, Yokohama, Japan \\ (Currently University of Fukui, Tsuruga, Japan, ohorim@u-fukui.ac.jp) \\ ${ }^{2}$ Research and Development Center for Earthquake and Tsunami, \\ Japan Agency for Marine-Earth Science and Technology, Yokohama, Japan \\ ${ }^{3}$ Earthquake Research Institute, University of Tokyo, Tokyo, Japan \\ ${ }^{4}$ Center for Integrated Disaster Information Research, Interfaculty Initiative in Information Studies, \\ University of Tokyo, Tokyo, Japan \\ ${ }^{5}$ Graduate School of Interdisciplinary Information Studies, University of Tokyo, Tokyo, Japan \\ (Currently Japan Patent Office, Tokyo, Japan) \\ ${ }^{6}$ Kochi Earthquake Observatory, Faculty of Science, Kochi University, Kochi, Japan \\ ${ }^{7}$ Kochi Earthquake Observatory, Faculty of Science, Kochi University, Kochi, Japan \\ (Currently Hiwasaki Group, Quick Software Corporation) \\ ${ }^{8}$ Earthquake and Tsunami Research Project for Disaster Prevention, \\ Japan Agency for Marine-Earth Science and Technology, Yokohama, Japan \\ (Currently Nagoya University, Nagoya, Japan)
}

\begin{abstract}
We have constructed a shallow underground structural model of Kochi City for an area $10.5 \mathrm{~km}$ east-west by $5.5 \mathrm{~km}$ south-north with a resolution of $125 \mathrm{~m}$, which could control seismic amplification in the short period up to $1 \mathrm{~s}$. By compiling the geological information given by the Committee of Kochi Geo-Hazard Evaluation (2011), we constructed a multilayered model overlying the engineering bedrock with an S-wave velocity of $700 \mathrm{~m} / \mathrm{s}$. Based on our newly developed model, the dispersion characteristics of theoretical surface waves at two sites were calculated and verified by comparison with observed data derived from our microtremor array experiments. The predominant periods along two north-south lines calculated from our model were coincident with previous observations derived from microtremor H/V spectral ratios by Mori et al. (2001). We also conducted a seismic response analysis using the synthesized ground motion data from the Central Disaster Management Council of Japan (2003) as the input motion applied to the basement of the developed subsurface structural model. We confirmed that the area where relatively high seismic intensity was predicted corresponded well with the area that was severely damaged during the 1946 Nankai Earthquake.
\end{abstract}

Key Words: Kochi City Area, Shallow Underground Structural Model, 125 m Grid, Borehole Data, Microtremor Array Measurements 


\section{INTRODUCTION}

Subduction of the Philippine Sea plate beneath the overlying Eurasian plate has been attributed to the occurrence of magnitude 8 class megathrust repeating earthquakes along the Nankai Trough, and has a history of causing severe widespread damage, especially in Western Japan (Tsuji (2003)). The Long-Term Evaluations of the Earthquake Research Committee of the Headquarters for Earthquake Research Promotion of Japan (2012) predicted high occurrence probabilities within the next 30 years (as of January 1, 2011) of $87 \%$ for an earthquake at Tokai, $70 \%$ for an earthquake at Tonankai, and $60 \%$ for an earthquake at Nankai. Moreover, it has been pointed out that from historical studies, these megathrust earthquakes may occur as a seismic linkage (Tsuji (2006)). To understand the potential for seismic linkages and the reoccurrence of these earthquakes, and to provide an estimation of seismic motion and tsunami heights and damage, large-scale research projects have been conducted by the Ministry of Education, Culture, Sports, Science and Technology, Japan (Special Project for Earthquake Disaster Mitigation in Urban Areas (2002-2006), Research for the Tonankai and Nankai Earthquakes (2003-2007), and the Project for Seismic Linkage for Tokai, Tonankai, and Nankai Earthquakes (2008-2012)).

Kochi City, the area of our interest, is an area where serious damage is expected in the occurrence of a major earthquake along the Nankai Trough. For example, during the Nankai Earthquake in 1946, Kochi City was subject to a series of complex disasters, such as a strong motion, land subsidence, a tsunami, and a long-lasting flood (Tsuji (2006). To mitigate these effects of past and potentially future disasters, countermeasures against the strong motion will be the most significant because correct behavior in response to any strong motion, which is the event that occurs first, will have a marked effect on a rapid evacuation from a tsunami. Therefore, to predict the ground motion properly, developing an enhanced soil model for use in a seismic response analysis is an important issue. In the urbanized area of Kochi City, most of the buildings are low- or medium-storied, so they can be greatly affected by short-period ground motions up to $1 \mathrm{~s}$, which may be highly amplified by shallow portions of the underground structure.

Based on the background above, we constructed a shallow underground structural model of Kochi City with an area of $10.5 \mathrm{~km}$ east-west by $5.5 \mathrm{~km}$ south-north with a resolution of $125 \mathrm{~m}$ (as shown in Fig.1). This could control the seismic amplification with a short period around $1 \mathrm{~s}$. By compiling the geological information open to the public, we constructed a multilayered model embedded over the engineering bedrock with an S-wave velocity of $700 \mathrm{~m} / \mathrm{s}$. Based on our newly developed model, we calculated the dispersion characteristics of theoretical surface waves at two sites, and compared them with observations derived from our microtremor array experiments. Next, we calculated the predominant periods along two north-south lines calculated from our model and compared them with previous observational data derived from microtremor $\mathrm{H} / \mathrm{V}$ spectral ratios conducted by Mori et al. (2001). Finally, we conducted one-dimensional seismic response analysis to improve our understanding of the spatial distribution of increments in seismic intensity. The synthesized ground motion data from the Central Disaster Management Council of Japan (2003) was used as the input motion applied to the basement of our developed subsurface structural model. The area where relatively high seismic intensity was predicted was compared with the zone that was severely damaged during the 1946 Nankai Earthquake.

\section{OVERVIEW OF THE GEOLOGICAL CHARACTERSITCIS OF THE KOCHI PLAIN}

Details of the geological characteristics of the Kochi plain are found in representative studies by Katto and Nishi $(1971,1972)$, and in the book, "The Ground Diagram of Kochi” by the Editorial Committee for the Ground Diagram of Kochi (1992), which compiles its work, and has been used by many researchers (e.g., Mori et al. (2001), Saito and Hasegawa (2007), Yatabe et al. (2008), and Hasegawa et al. (2009)). Katto and Nishi $(1971,1972)$ suggested that, in the broad sense, the Kochi plain is separated into alluvial lowland embedded in the rift valley in the western part, and as an elevated fan in the eastern part. In addition, the former may be recognized as the Kochi plain in the narrow sense. 
In this paper, we modeled the Kochi plain as taken in the narrow sense. Regarding the Kochi geomorphological features, as explained by Katto and Nishi (1971, 1972), the Mikabu tectonic line and the Butsuzo tectonic line, both of which run in the east-west direction, divide the Kochi plain into three regions: the Sanbagawa metamorphic belt, the Chichibu belt, and the Shimanto metamorphic belt, from north to south, respectively. In general, the geological dating becomes younger moving southward. The Kochi plain is considered to be a structural basin, which extends mainly in the middle and south portions of the Chichibu belt, and is covered with diluvial (Pleistocene) and alluvial (Holocene) deposits (Katto and Nishi $(1971,1972)$ ). Most of the rivers, such as the Kagami, Kuma, and Kokubu Rivers, run in an east-west direction, and join together to flow into Urado Bay or into the mouth of the Kokubu River. Each river forms an alluvial fan in the upper stream, a natural levee and back marsh in the middle stream, and a delta in the lower stream. The delta facing Urado Bay and the mouth of the rivers is affected significantly by changes in sea level. In addition, land reclamation and other artificial works since the Edo period have contributed to the urbanized area in Kochi City in its current form (Katto and Nishi (1971, 1972), Editorial Committee for the Ground Diagram of Kochi (1992).

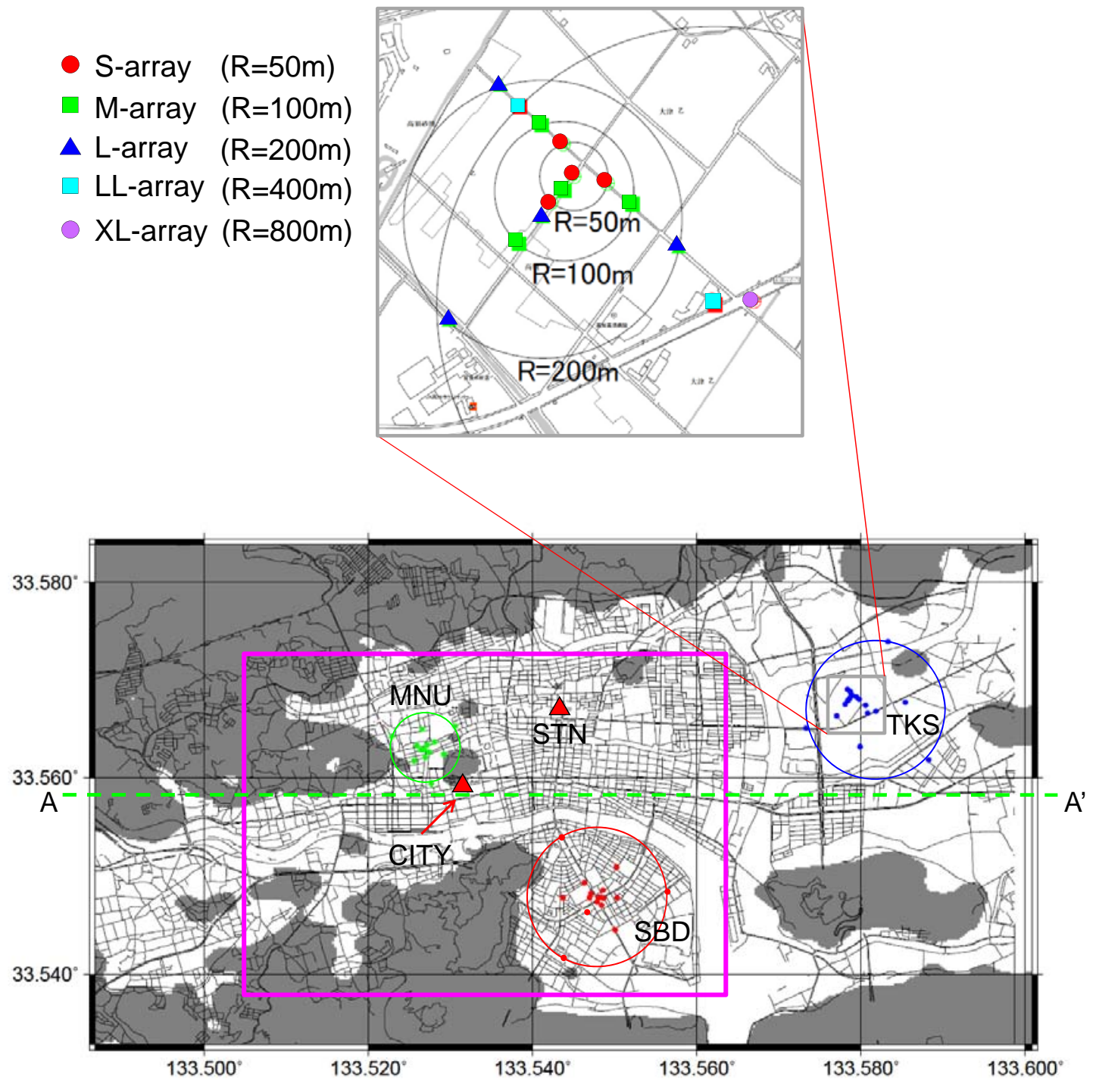

Fig. 1 Map showing the target area in Kochi plain. 


\section{COMPILATION OF THE GEOLOGICAL INFORMATION ON KOCHI CITY}

Bore data on the Kochi plain has been collected by Katto and Nishi (1971, 1972), and the modeling of the shallow underground structure has been carried out by several organizations to predict the ground motion and to estimate damage. In the following section, we provide an overview of representative works on the geological information, including bore data, geomorphologic classification, underground structural models, and the existing database. Then, we describe our modeling policy.

Katto and Nishi $(1971,1972)$ collected data from about 600 bores and reported on the basement depth of the Holocene layer and a volcanic ash layer, the thickness of both layers, and on three geological sections passing through the Harimaya bridge. They pointed out that the volcanic ash layer named the S1v layer, deposited about 5,500 years ago, could be a key layer for understanding the formation process of the alluvial deposits in the Kochi plain. They also pointed out that compared with the large volume of bore data on the Holocene layer, the data for the Pleistocene layer are limited. Their comments are still very significant for this study.

In "The Ground Diagram of Kochi” from the Committee of the Ground Diagram of Kochi (1992), data from approximately 1,500 bores were collected and compiled, and then the depth of the Holocene bottom, the top depth of bedrock, and 13 geological sections were reported. Moreover, 432 bore logs were published. Previous work by Katto and Nishi $(1971,1972)$ was mostly adopted in the interpretation of the geology and data.

Based on the bore data, geomorphologic classifications, and PS logging data, the Central Disaster Prevention Council, Japan (2003) constructed the subsurface structure at a resolution of $1 \mathrm{~km}$. The shallow and deep portions were modeled separately and then combined to evaluate the strong ground motion and induced damage. The subsurface structure is available to the public.

Kochi Prefecture (2004) conducted a research entitled, "Secondary Basic Research for Measures against Earthquake in Kochi Prefecture", using bore data, geomorphologic classification maps, and surface geology maps, and the subsurface structure covering the entire Kochi Prefecture at a resolution of $250 \mathrm{~m}$ was constructed. This was used to evaluate the strong ground motion and induced damage. For the S-wave velocity structure in the shallow layers overlying the engineering bedrock with an S-wave velocity of $700 \mathrm{~m} / \mathrm{s}$, the study used the empirical relationship between the $\mathrm{N}$-value and S-wave velocity estimated by Central Disaster Prevention Council, Japan (2003). For the deep structure between the engineering bedrock and the seismic bedrock with an S-wave velocity of 2,900 $\mathrm{m} / \mathrm{s}$, the study's methodology and modeling referred to works by the Central Disaster Prevention Council, Japan (2003). For Kochi City, 27 types of soil classification were carried out for the Holocene and Pleistocene layers.

The Shikoku Geo-Informatics Council (2005) developed the "Shikoku Geo-Informatics Database". They collected data from 3,382 bores in the Kochi plain and compiled the data on a CD-ROM, whose use is limited to affiliated members of the council. The National Research Institute for Earth Science and Disaster Prevention constructed the "Japan Seismic Hazard Information Station (J-SHIS)" database. This features a GIS-based geomorphologic classification map covering all of Japan with a resolution of $250 \mathrm{~m}$, which has relational linkage to the AVS30 value (the average shear velocity in the upper $30 \mathrm{~m}$ of the ground), the amplification factor of the maximum velocity between the engineering bedrock and the surface. These data are open to the public via the Internet.

The Kochi Disaster Information and Sub-structure Evaluation Committee (2011) collected data from about 1,750 bores and constructed shallow subsurface structure models with a resolution of 125 $\mathrm{m}$ using about 1,500 points. They also constructed about 150 geological sections. All the data that were collected, compiled, and constructed are open to the public via the Internet. Bore data are available in xml file format (Ministry of Land, Infrastructure, Transport and Tourism (2008)), and the shallow structural model and geological sections are archived in pdf format. The 15 types of soil they classified includes: 11 types for the Holocene and Pleistocene layers, 3 types from weathered rocks, and 1 type from the engineering bedrock. The geological sections include analog bore data, which are not open to the public in a digital form, such as the data featured in "The Ground Diagram of Kochi" or private data. This information is closed to the public, and digital data would be useful for checking 
the estimated depth of the engineering bedrock.

As mentioned above, a large volume of geological information on the Kochi plain, such as bore data, subsurface models, and geological sections has been accumulated in the literature. Among these, recent work by the Kochi Disaster Information and Sub-structure Evaluation Committee (2011) is the most convenient for us, considering the accessibility of the data. Based mainly on their open data, we constructed a shallow subsurface structural model of the Kochi plain with a resolution of $125 \mathrm{~m}$. We also used their 15 types of soil classification, as shown in Table 1.

\section{MODELING METHODOLOGY}

In this study, considering the distribution of the geological information provided by the Kochi Disaster Information and Sub-structure Evaluation Committee (2011), we modeled the urbanized area of Kochi City, as shown in Fig.1. The area studied was $10.5 \mathrm{~km}$ wide east-west and $5.5 \mathrm{~km}$ long north-south. In Fig.1, the red triangles denote the location of Kochi's railway station labeled "STN" and the City Hall labeled "CITY". The area in the violet rectangle approximates the area shown in Fig.13. These colors are common to the other figures in this work. Next, we will discuss how we constructed the model.

First, we will discuss in detail the summarized results of the Kochi Disaster Information and Sub-structure Evaluation Committee (2011). They collected and released data from 1,054 bores to the public in xml file format (Ministry of Land, Infrastructure, Transport and Tourism (2008)), as discussed above. In Fig.2, we show the distribution of these data in the target area. Among these, data from 387 bores (denoted by the red dots in Fig.2) reached the engineering bedrock at the bottom of the borehole. Most of the data seemed to be obtained for construction surveys, such as roads or buildings, so they tended to be aligned in a straight line or were concentrated in urbanized areas. The location of the bore data covered 196 meshes with a resolution of $125 \mathrm{~m}$. The Committee also constructed 1,465 structural models (denoted by the white dots in Fig.2) corresponding to meshes with a resolution of $125 \mathrm{~m}$, and released these to the public in pdf file format. Among these, 1,200 structural models (denoted by the orange dots in Fig.2) reached the bottom of the engineering bedrock. We surveyed the data, considered the three-dimensional distribution of the data, and determined three interfaces whose depth could be estimated properly using interpolation: the top of the S1v layer, the bottom of the Holocene layer, and the top of the engineering bedrock (i.e., the bottom of the Pleistocene layer). We called this stage "Step 1" in our modeling.

Next, using the three interfaces, we interpolated their surfaces and defined the depth from the surface determined using the DEM data of the Geospatial Information Authority of Japan (2008). We called this stage "Step 2". Interpolation of the top of the engineering bedrock using only the bore data in xml format resulted in too shallow a depth at some locations when compared with geological sections reflecting the depth of the engineering bedrock. To remedy this, we digitized the depth of the engineering bedrock (denoted by the orange lines in Fig.2) when it appeared in the 43 geological sections (denoted by the green lines in Fig.2), and treated it as additional bore data in our interpolation. When the bore data did not reach the engineering bedrock, we checked whether the interface determined by the interpolation was deeper than the deepest part of the data. We could easily determine the interface regarding the bottom of the Holocene layer, but for the top of the S1v layer, we had to consider the following when the S1v layer did not appear in the data. We examined which layers were above or below the S1v layer for the 11 Holocene layers. As a result, we divided groups into an upper layer (B, M1, G1, and G1s) and a lower layer (G2b, S1b, and M2). When the S1v layer did not appear in the bore data, we assumed the thickness of the S1v layer was $0 \mathrm{~m}$, and located it between the upper layer and lower layer groups. In this way, we finally determined the top of the S1v layer. In Fig.3, we show the three interfaces that were determined using the method discussed above. On interpolation of the data, we used a spline technique based on the minimum curvature algorithm of Wessel and Smith (1990, 1999). As can be seen in Fig.3, the depth of the engineering bedrock was relatively shallow in the western part of Kochi station. In addition, in the eastern part from the Sambashi-dori area (SBD in Fig.1) to the Takasu area (TKS in Fig.1), the depth of the engineering bedrock was deep. The depth distribution of the Holocene layer seemed to be similar to that of the 
engineering bedrock.

We will now explain how we treated the bore data that did not reach the top of the engineering bedrock. Hasegawa et al. (2009) examined the geological characteristics of the Kochi plain and pointed out that the typical structure of the Pleistocene profile was as multilayers in which mud and gravel were stacked alternately. They also proposed the layered structure shown in Fig.4(a), which they considered to be the reference model of the Kochi plain. Using the Pleistocene section of this reference model, we conducted the following to supplement for the bore data that did not reach the top of the engineering bedrock. For example, for the bore data shown in Fig.4(b), to extend the data to the top of the engineering bedrock estimated from interpolation, we supplemented the limited amount of data using the Pleistocene region at the corresponding depth taken from the reference model in Fig.4 (a). The Pleistocene section in Hasegawa et al.'s (2009) model consists of many layers, such as M3, M4, ... M7 for the mud layers, and G2, G3, ... G6 for the gravel layers. In our modeling, we used the soil layer classification shown in Table 1, so we modeled the Pleistocene layer using alternate layers of M3 and G2 only. We called this stage "Step 3". From this treatment, hereafter, it can be assumed that all bore data used in the modeling were supposed to reach the top of the engineering bedrock.

Finally, we divided the target area into a mesh with a resolution of $125 \mathrm{~m}$. For the parts of the mesh that did not have any bore data, we filled these with the nearest data, and adjusted the layer thickness proportionally between the interfaces. We called this stage "Step 4". This step-by-step modeling procedure is shown in Fig. 5 as an east-west geological section, corresponding to the line A-A' in Fig.1.

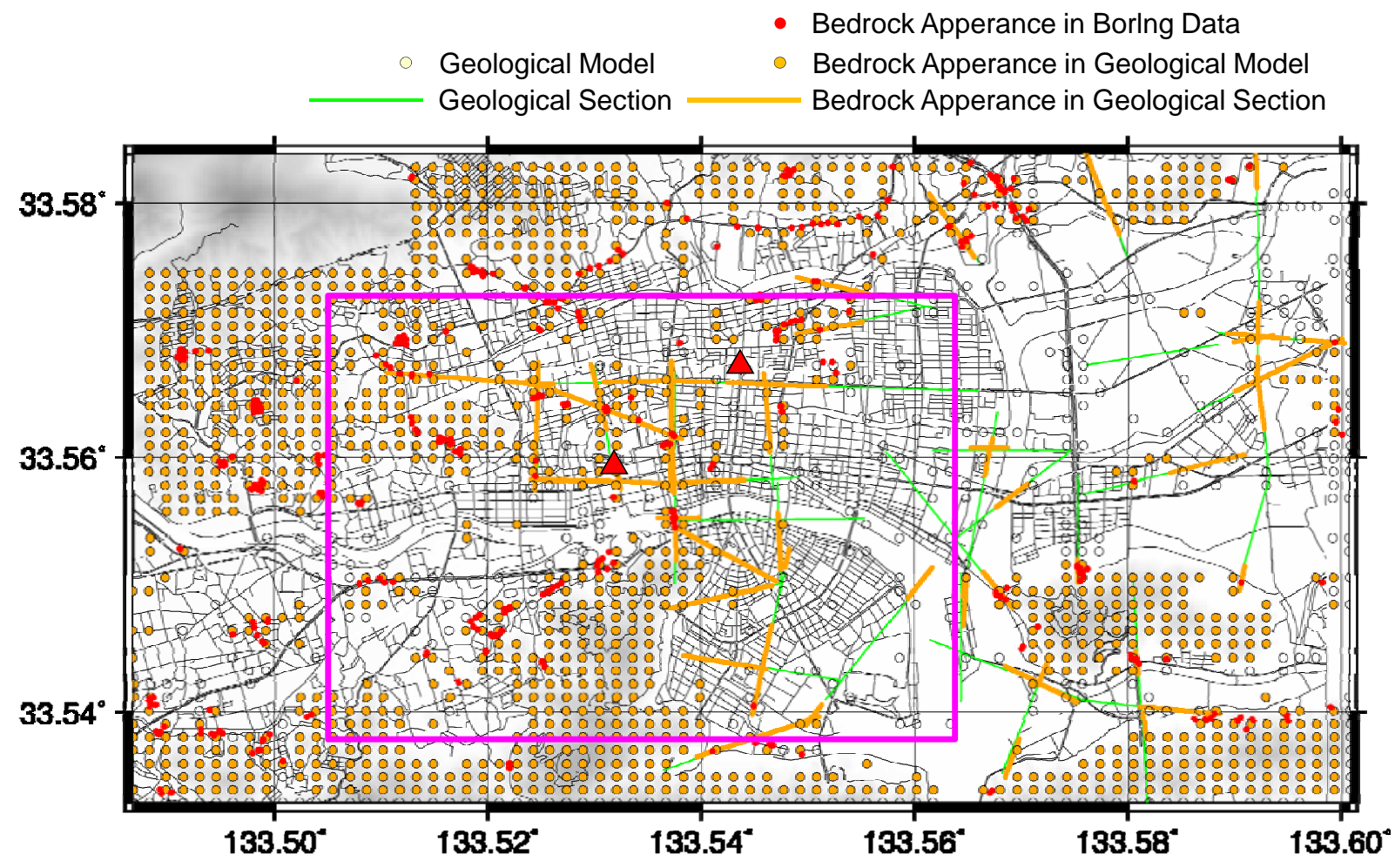

Fig. 2 Map showing the spatial distribution of the geological information used in the study. 
(a)

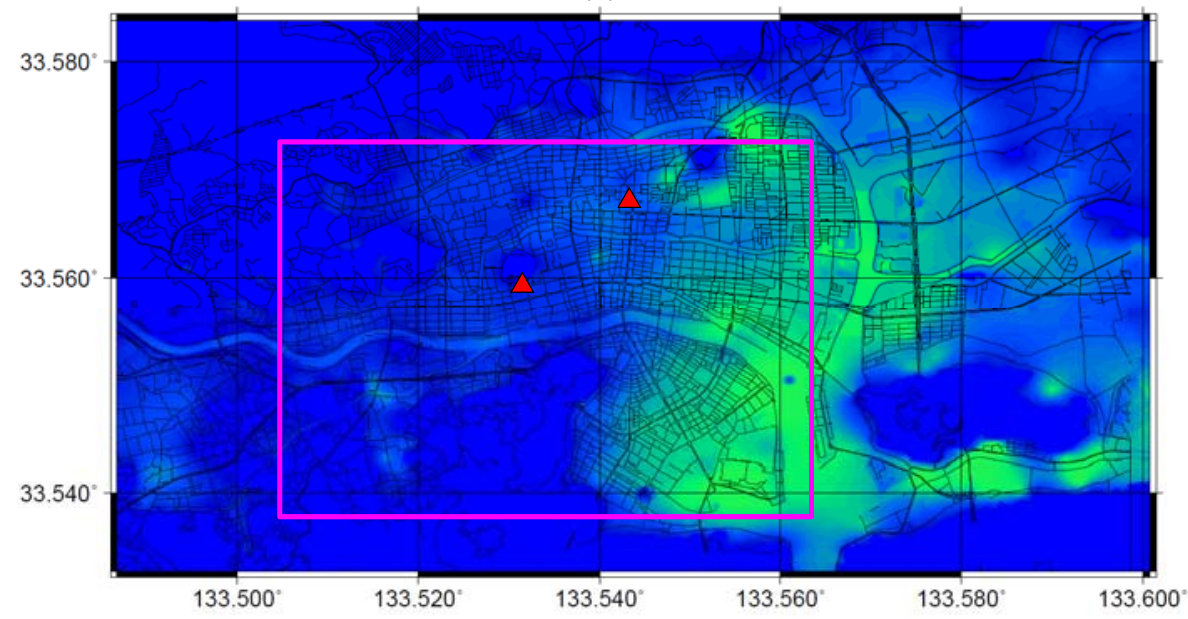

(b)

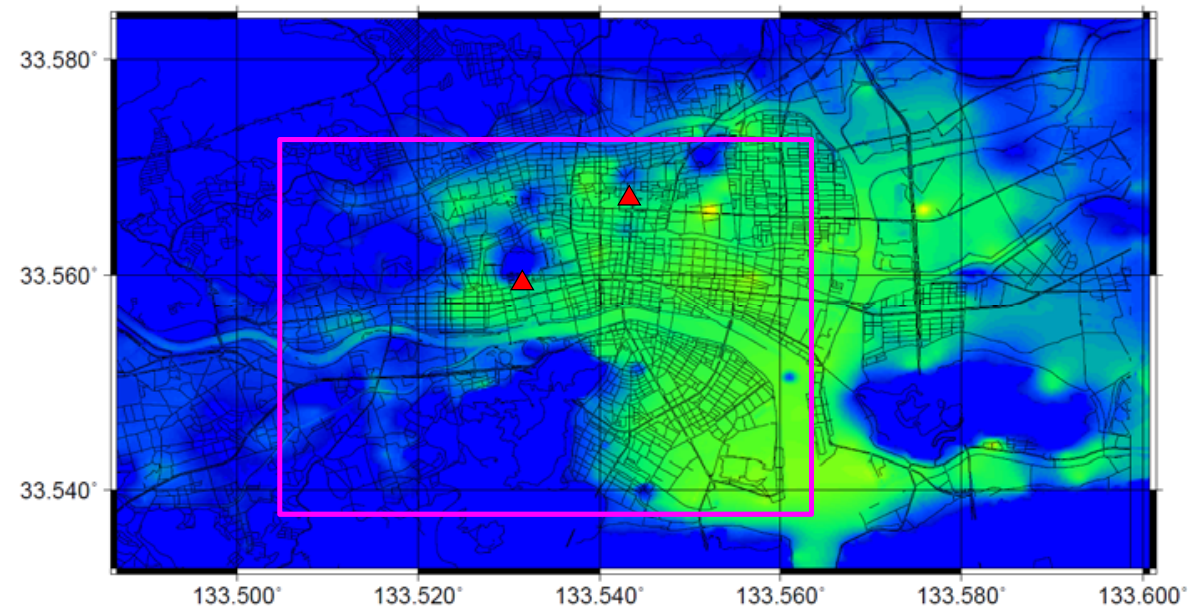

(c)

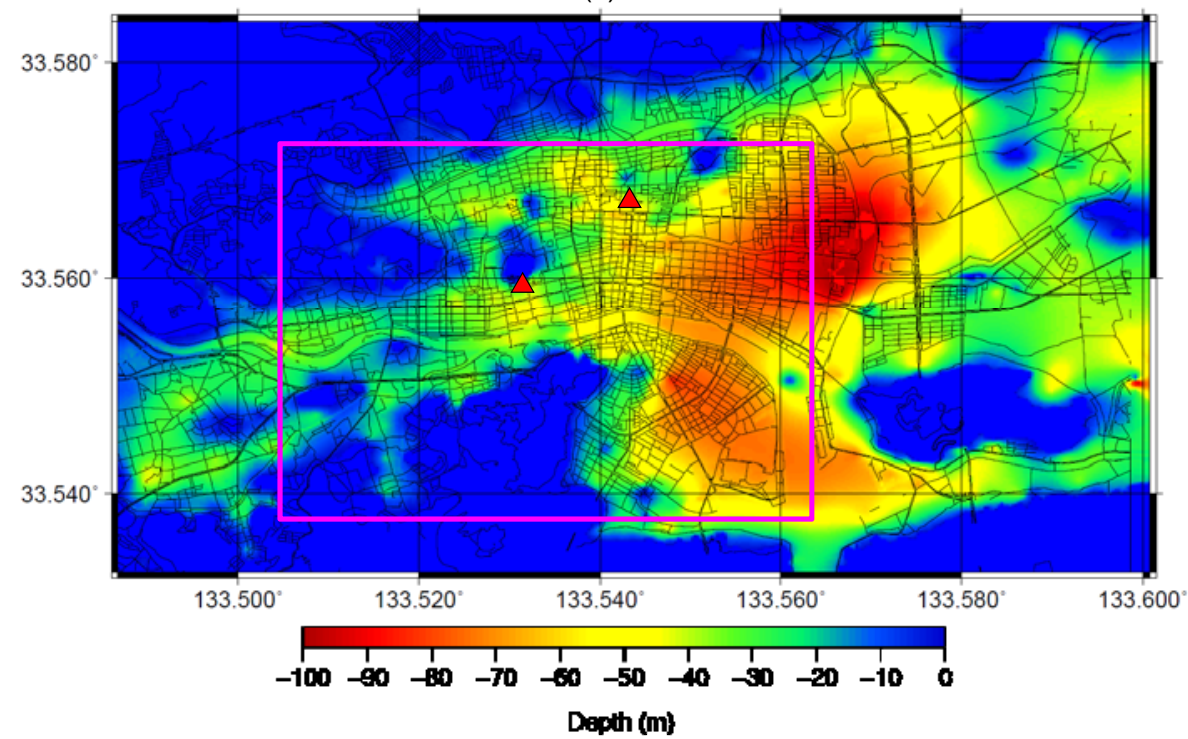

Fig.3 Map showing the depth of interpolated interfaces. (a) Top of the S1v layer, (b) Bottom of the Holocene layer, and (c) Top of the engineering bedrock. 
(a) Model by Hasegawa et al. (2009)

(b) Extended Boring Data

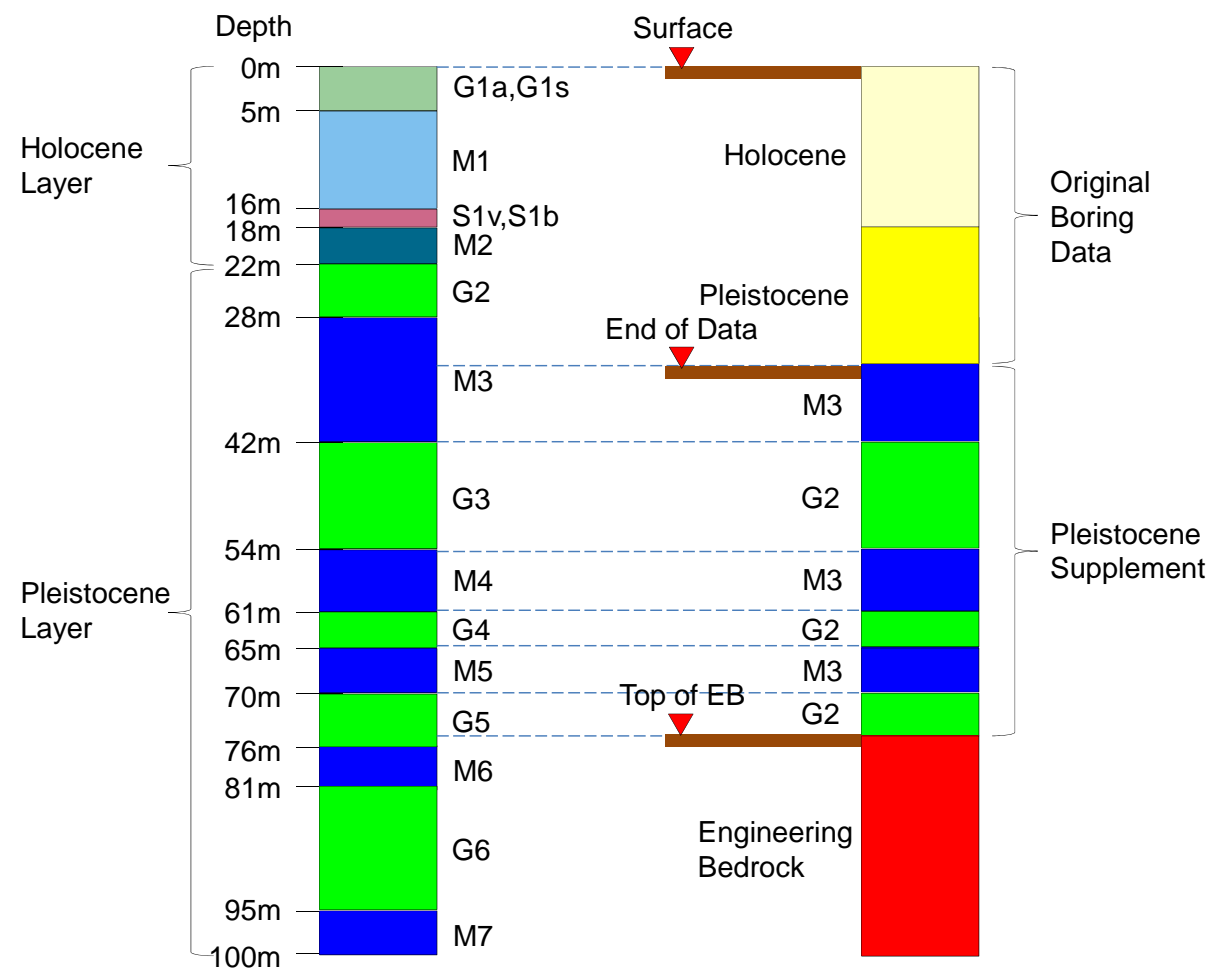

Fig. 4 Treatment for the bore data that did not reach the top of the engineering bedrock.

\section{S-WAVE VELOCITY STRUCTURE AND VERIFICATION OF THE MODEL}

We assigned the S-wave velocity to each layer as follows. As discussed in Section 3, we understand much of the geological information accumulated so far regarding the Kochi plain, but when it comes to the PS logging data, we only have few data, and none deeper than $30 \mathrm{~m}$ (Central Disaster Prevention Council, Japan (2003)). Microtremor array measurements are considered to be an alternative method for estimating the S-wave velocity structure instead of PS logging data. However, the practical application of such measurements has not been reported for the Kochi plain (Fujiwara (2009)). Recently, microtremor array measurements were carried out at three areas in and around the Kochi plain: at Tosa City, Kochi City, and Tosa-Yamada City (Miyakoshi, personal communication). PS logging data can be found in some of the literature (Hasegawa et al. (2009), Hiroi et al. (2010)). However, none of the xml files we collected included any PS logging data. As a result, we concluded that the information regarding S-wave velocity for Kochi City is sparse. To elucidate the S-wave velocity of the layered structure, the Kochi Prefecture (2004) referred to the empirical relationship between the N-value and the S-wave velocity as proposed by the Central Disaster Prevention Council, Japan (2003). The Kochi Disaster Information and Sub-structure Evaluation Committee (2011) also calculated this in the same way as the Kochi Prefecture (2004) did. In this study, we constructed a subsurface model with a resolution of $125 \mathrm{~m}$ based on the soil layer classification adopted by the Kochi Disaster Information and Sub-structure Evaluation Committee (2011). Their soil material properties data are open to the public. With reference to their data, we decided on the material properties shown in Table 1. 

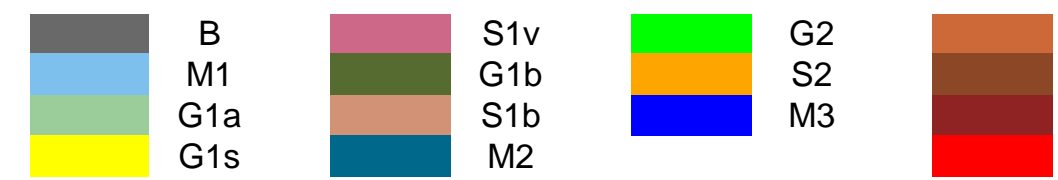

(a)

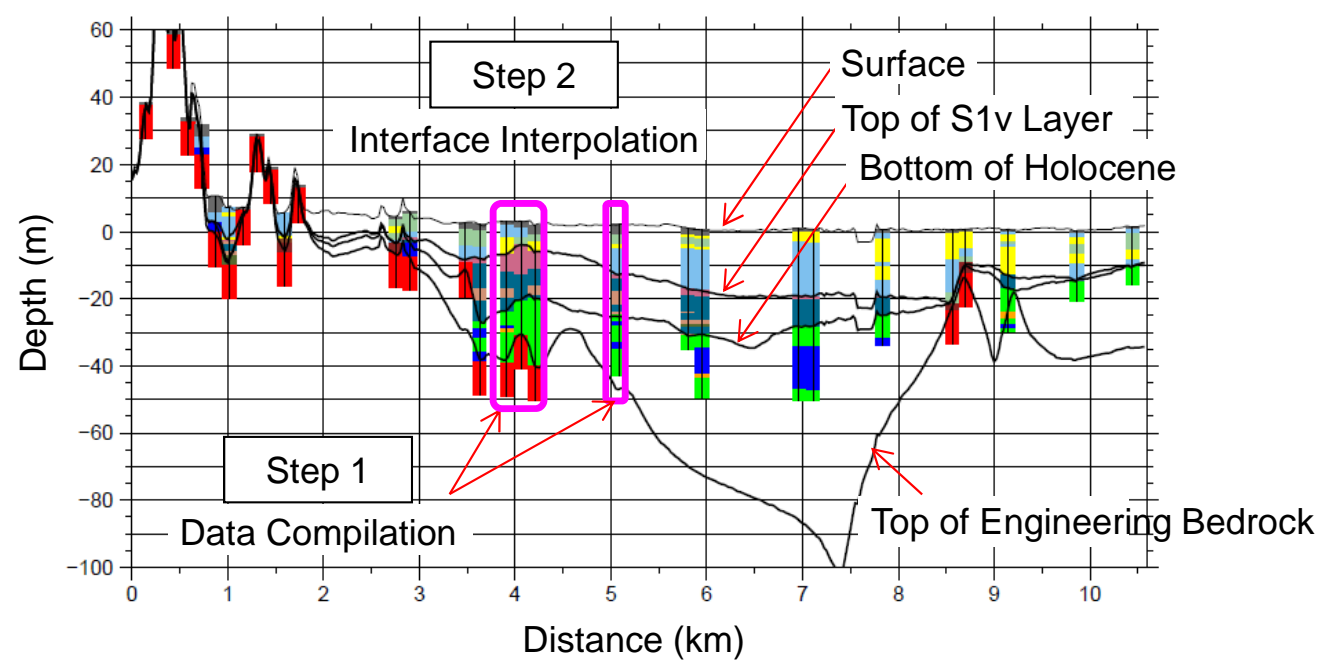

(b)

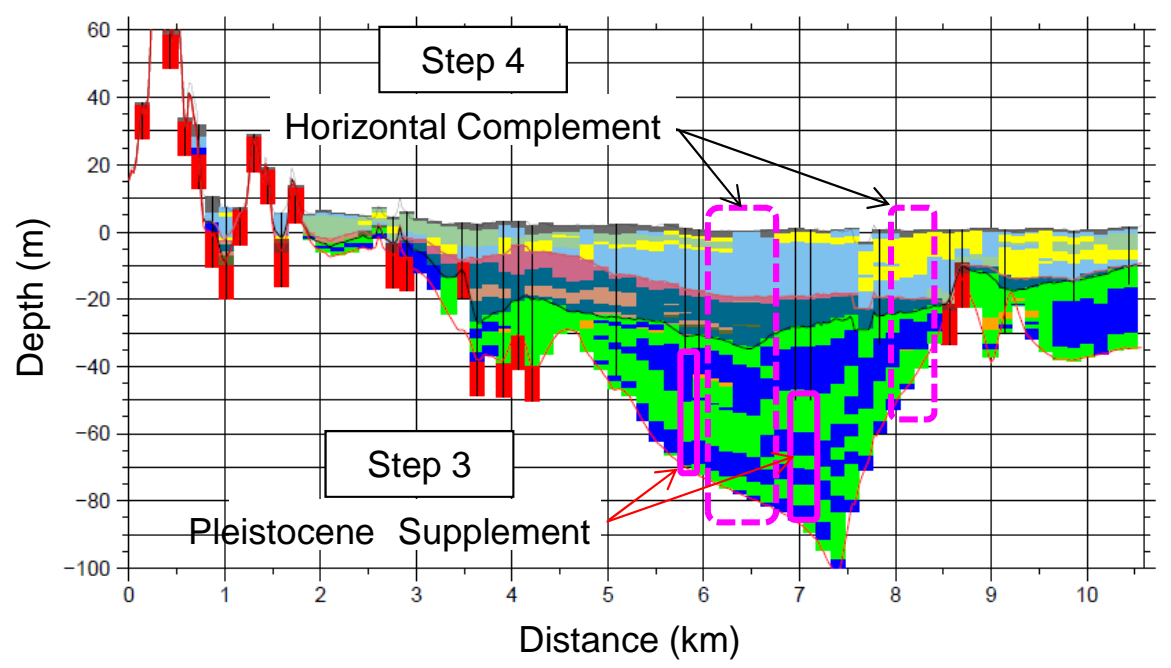

Fig.5 An east-west geological section in a line A-A' (in Fig.1) to illustrate the step-by-step modeling procedure. (a) Step 1 and Step 2. (b) Step 3 and Step 4. (Soil classification is found in Table 1.)

Next, to validate the S-wave velocity structure used in this study, we carried out microtremor array measurements and estimated the phase velocity of the surface waves. The microtremor array measurements were performed at three areas where we deployed the array during daylight on February 20-21, 2010: Sambashi-dori, Marunouchi (MNU), and Takasu. In Fig.1, we show the location of these areas. At SBD and MNU, which are relatively urbanized areas, we used seven seismometers and deployed two nested triangles. A seismometer located at the center was surrounded by three sets of seismometers located on a circle with radius, R. Another three sets were located on a circle with radius, 2R. In this way, we recorded simultaneous data observations. The radius was set to $R=50$ and $200 \mathrm{~m}$ for $\mathrm{MNU}$, and $\mathrm{R}=50,200$, and $400 \mathrm{~m}$ for SBD. For TKS, an agricultural area, we had to install seismometers on the agricultural roads, and so we used eight seismometers with an offset between the centers of two different-sized arrays. The radius $\mathrm{R}$ was the same as in the SBD measurements. In the 
Table 1 Soil material properties.

\begin{tabular}{|c|c|c|c|c|c|c|}
\hline \multirow{2}{*}{ No. } & \multicolumn{3}{|c|}{ Soil Layer Classification } & Soil & $\begin{array}{c}\text { Density } \\
\left(\mathrm{kN} / \mathrm{m}^{3}\right)\end{array}$ & $\begin{array}{c}\text { S-wave } \\
\text { Velocity } \\
(\mathrm{m} / \mathrm{s})\end{array}$ \\
\cline { 2 - 7 } & Color & Index & Layer & A & 18 & 175 \\
\hline 1 & & B & Surface Soil & Ac & 17 & 155 \\
\hline 2 & & M1 & Mud Deposits 1 & Ag & 19 & 200 \\
\hline 3 & & G1a & Gravel Deposits 1a & Ag & 20 & 160 \\
\hline 4 & & G1s & Gravel Deposits 1s & As & 15 & 190 \\
\hline 5 & & S1v & Sand Deposits 1 (Volcanic) & Ag & 20 & 215 \\
\hline 6 & & G1b & Gravel Deposits 1b & As & 19 & 185 \\
\hline 7 & & S1b & Sand Deposits 1b & Ac & 18 & 170 \\
\hline 8 & & M2 & Mud Deposits 2 & Dg & 20 & 320 \\
\hline 9 & & G2 & Gravel Deposits 2 & Ds & 19 & 260 \\
\hline 10 & & S2 & Sand Deposits 2 & Dc & 18 & 270 \\
\hline 11 & & M3 & Mud Deposits 3 & - & 20 & 400 \\
\hline 12 & & WRG & Weathered Rock (Gravelly) & - & 20 & 400 \\
\hline 13 & & WRM & Weathered Rock (Silty) & - & 20 & 400 \\
\hline 14 & & WRS & Weathered Rock (Sandy) & - & 21 & 700 \\
\hline 15 & & EB & Engineering Bedrock & - & 21 \\
\hline
\end{tabular}

upper portion of Fig.1, we show an enlarged map of the TKS area. According to the geomorphologic classification by J-SHIS, SBD includes a natural levee, a delta, and reclaimed land, while MNU has a natural levee and valley plains, and TKS has reclaimed land.

In our measurements, we used seven or eight sets of portable seismometers (acceleration sensor = JEP-6A3 (Mitsutoyo Co., Japan) and a 24-bit logger (DATAMARK LS-7000XT, Hakusan Co., Japan)), owned by the Earthquake Research Institute, University of Tokyo, Japan. Data were recorded for 30 min using a sampling frequency of $100 \mathrm{~Hz}$. The data set was divided into three subsets of 10 min for convenience of analysis. In our spectral analysis, we calculated the cross spectra between two sensors using segments containing 1 min of waveform data and averaged the spectra from 10 segments. The cross spectrum from each segment was then smoothed using a Parzen window with a width of 0.2 Hz. The basic procedure was the same as used by Ohori et al. (2002). Applying the spatial autocorrelation (SPAC) method of Okada et al. (1994) to the vertical component waveform data obtained from each array measurement, we first estimated the phase velocity and compared it with the Rayleigh wave fundamental mode calculated from our subsurface model. In Fig.6(a), we show sample results for the SBD area. In Fig.6(a), the estimated phase velocity is shown together with the calculated phase velocity, whose S-wave velocity structure in the shallow part is shown in Fig.6(b). The deep-layered model proposed by the Central Disaster Prevention Council, Japan (2003) was connected to the bottom of this model. The sensitivity of the phase velocity of the P-wave velocity $(\mathrm{Vp})$ was not as high as that of the S-wave velocity (Vs), so we simply determined it from the following relationship: $\mathrm{Vp}=5.099 \mathrm{Vs}$. The dispersive phase velocity results from each array were selected according to the detection rule that the corresponding wavelength must be longer than twice the distance of the array radius. In Fig.6(a), the straight dotted line corresponds to a wavelength of 100 $\mathrm{m}$, which is twice the minimum radius of $50 \mathrm{~m}$. From Fig.6 (a), it can be seen that the matching between the observed phase velocity and the calculated phase velocity is good. Strictly speaking, we derived very few data from observations. Unfortunately, in the daytime in SBD, there was much traffic, so this may have affected the data quality significantly. In addition, the spectral energy $<2 \mathrm{~Hz}$ was generally weak in the three areas. We calculated the medium response of the Rayleigh waves based on the model shown in Fig.6(b), and confirmed that it decreased in the frequency range $<2 \mathrm{~Hz}$. We assumed that the spectral energy was weak because of the weather characteristics during the observations, as well as the seismic characteristics of the subsurface structure. 

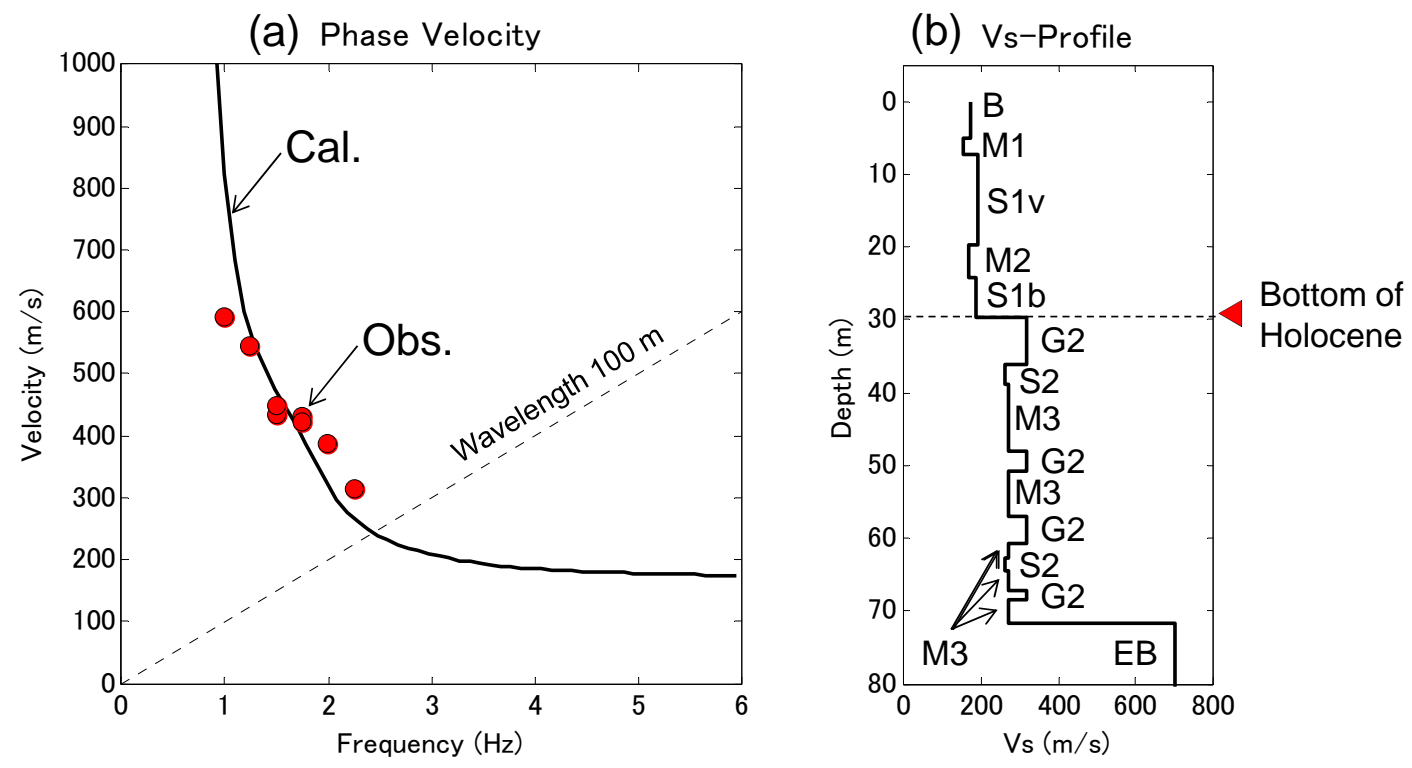

Fig.6 Phase velocity and the S-wave velocity model for Sambashi-dori (SBD).

(a) Phase Velocity

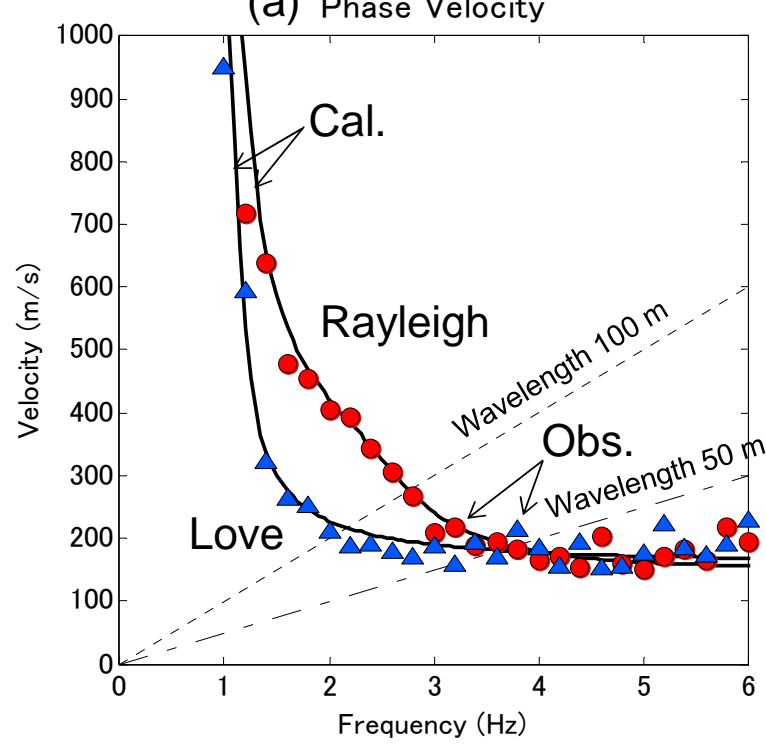

(b) Vs-Profile

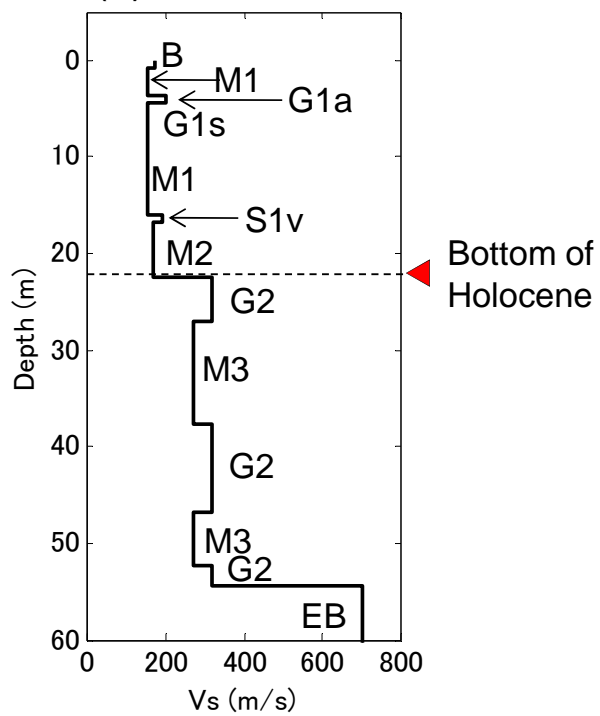

Fig.7 Phase velocity and the S-wave velocity model for Takasu (TKS).

Compared with the vertical components, the horizontal components were stronger in the frequency range $<2$ Hz. Therefore, we analyzed these using the FK method. We applied Capon's (1969) method to the vertical components, and Saito's (2007) method to the radial and transverse components. A similar application was carried out by Tokimatsu et al. (1995), applying Capon's (1969) method to all three components. We note that Saito (2007) pointed out a singularity, implying the azimuthal dependence at the origin of the wavenumber domain in the analysis of the horizontal components. As a result, our analysis using the FK method failed to improve the results derived from the SPAC method for SBD and MNU, but was successful for TKS. As already discussed, we conducted observations using two sized arrays simultaneously and for TKS, we used eight seismometers, with 
array radii of 50 and $100 \mathrm{~m}$, which had a $25 \mathrm{~m}$ offset between the central points. In Fig.7(a), we show the phase velocity results from the vertical components compared with the theoretical values of the fundamental mode Rayleigh waves calculated using the subsurface structure from the model we constructed. In Fig.7(b), we show the phase velocity results from the transverse components compared with the theoretical values of the fundamental mode Love wave. From these figures, a good agreement was found between the observed phase velocities and calculated phase velocities. The detection limit of the minimum wavelength was considered to be twice the minimum sensor distance, which was 50 $\mathrm{m}$ in this case. The two straight lines shown in the figures correspond to wavelengths of 50 and $100 \mathrm{~m}$.

For MNU, we did not obtain any successful results because the coherence between the stations we deployed was too low, even for the array with a radius of $50 \mathrm{~m}$. We examined the predominant period from the $\mathrm{H} / \mathrm{V}$ spectral ratio and found that the peak frequency changed from station to station. This suggests to us that the subsurface structure beneath the area of MNU changes rapidly in the lateral direction, beyond our expectation, so the assumption of a horizontal layered structure just beneath the array must be incorrect. Because of space limitations, we have not shown these results. To estimate the underground structure with a steep lateral irregularity, the microtremor records must be analyzed using a more enhanced method (e.g., Uebayashi (2003)).

\section{BASIC CHARACTERISTICS OF THE MODEL}

Based on the model we constructed, we calculated the amplification characteristics subjected to the vertically incident plane $S$-wave at the bottom of the engineering bedrock using one-dimensional wave propagation theory, and we mapped the spatial distribution of the predominant period, as shown in Fig.8. As we assumed the depth of the top of the engineering bedrock shown in Fig.3(c), the predominant period shortens west of Kochi station, and in contrast, it lengthens to the east.

Next, in Figures 9(a) and 10(a), we compare the distributions of the predominant period derived from our model with the published results of Mori et al. (2001), which were determined using the peak of the $\mathrm{H} / \mathrm{V}$ spectrum of microtremor measurements along two lines, E-E' and F-F', in Fig.8. In Figures 9(b) and 10(b), we show the bottom depth of the Holocene layer and the depth of the top of

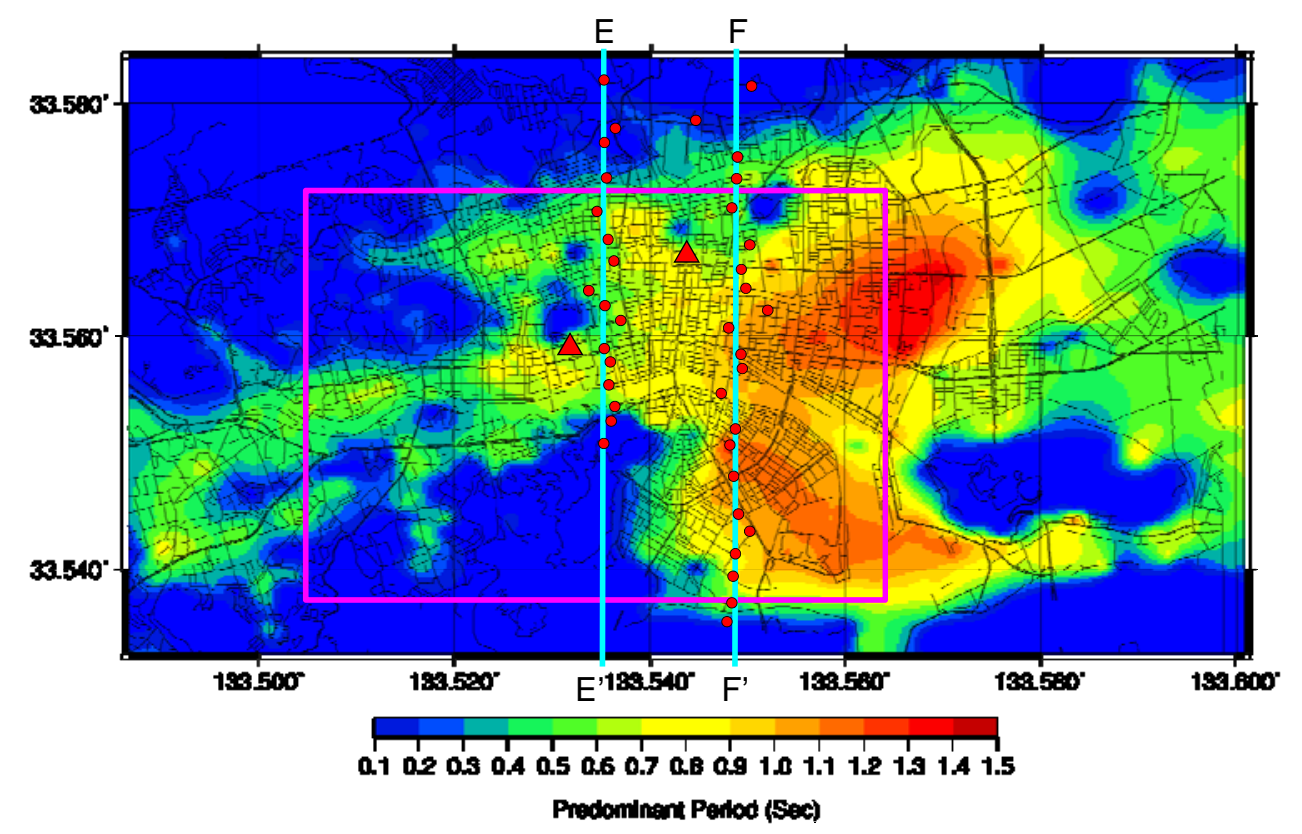

Fig.8 Map showing the spatial distribution of the predominant period. 
the engineering bedrock extracted from our model. Looking at these figures, we can see a good agreement between the predominant period calculated using our model and the observed data of Mori et al. (2001). We can also see that the spatial variance of the predominant period seems to depend on the depth of both the bottom of the Holocene layer and the top of the engineering bedrock. We note that the western part of the target area must be examined in future work.

Mori et al. (2001) determined the S-wave velocity empirically from the N-value, and estimated the predominant period using the quarter rule of the wavelength, and compared it with the observed data. A comparison for the line E-E' showed good matching, and they considered that the spatial variation of the predominant period corresponded well with the basement depth. On the other hand, the matching for the line F-F' was basically good, but looks slightly inferior compared with that for the line E-E', and they considered that the depth of the top of the engineering bedrock was not clear for line F-F'. Mori et al. (2001) assumed that the steep peak observed in the H/V spectra suggested a high contrast of the S-wave velocity between the surface layers and the engineering bedrock. They also pointed out that the predominant period increased proportionally with the thickness of the surface layers. In Fig.10(a), a good matching of the predominant period between calculations using our model and the observations of Mori et al. (2001) can be seen, which supports the estimation of the basement depth along line F-F' in our modeling as being reasonable. Using the model constructed in this study, we checked the relationship between the predominant period, Tp, the depth of the bottom of the Holocene layer, $\mathrm{Dh}$, and the depth of the top of the engineering bedrock, Dp. As a result, we derived the following equation: $\mathrm{Dh}=25.9 \times \mathrm{Tp}$, with a correlation factor of 0.923 , and $\mathrm{Dp}=70.1 \times \mathrm{Tp}$, with a correlation factor of 0.981 . We omitted the figure, but it can be envisaged that Tp has an approximately proportional relationship to both Dh and Dp. The relationship between Tp and Dh continues until Tp reaches a value of $1.2 \mathrm{~s}$. For a period $>1.2 \mathrm{~s}$, the proportional relationship between $\mathrm{Tp}$ and Dh appears to be invalid, but remains valid between Tp and Dp. These characteristics can explain the difference in the correlation factors discussed above. The slight difference in correlation factors implies that the predominant period should be evaluated considering the subsurface structure up to not only the bottom depth of the Holocene layer, but also the depth of the top of the engineering bedrock. The average S-wave velocity of the entire model we constructed was $167 \mathrm{~m} / \mathrm{s}$ for the Holocene layer and $296 \mathrm{~m} / \mathrm{s}$ for the Pleistocene layer. Using these values, we approximated the predominant period for each $125 \mathrm{~m}$ mesh and compared it with the data from the detailed calculations discussed above. These showed a good matching with a correlation factor of 0.996. Hiroi et al. (2010) carried out conventional microtremor measurements across Kochi City and examined the relationship between the predominant period from the $\mathrm{H} / \mathrm{V}$ spectra and the depth of the top of the engineering bedrock. The relationship they derived of $\mathrm{Dp}=70 \times \mathrm{Tp}$ agrees with the results of the model we constructed.

Next, using the subsurface model constructed in this study, we carried out a one-dimensional wave propagation analysis subjected to the vertically incident plane waves to calculate the strong ground motion in a future Nankai earthquake. As the input motion applied to the engineering bedrock with an S-wave velocity of $700 \mathrm{~m} / \mathrm{s}$, we used the synthetic waveform expected at the Kochi City Hall, which the Central Disaster Prevention Council, Japan (2003) calculated for promotion of countermeasures against a future Nankai earthquake (M8). In Fig.11, we show the acceleration waveforms used as the input motion, whose maximum acceleration and seismic intensity were $346 \mathrm{~cm} / \mathrm{s}$ and 5.74 , respectively. In our analysis, the quality factor of each layer was assumed to be Vs/15. We treated the properties of soil materials as being linear, so the seismic response at the surface became strong. Considering the high strain level, the calculated seismic response may be considered unrealistic. Therefore, we calculated increments of the seismic intensity against the so-called engineering bedrock outcrop waves, and show the spatial distribution of the seismic intensity in Fig.12. In our analysis, we did not consider any amplification effect of the surface layers on the vertical components. From Fig.12, it can be seen that the areas showing a large increase in seismic intensity are distributed in the eastern side with respect to Kochi station. In addition, the spatial distribution with increasing seismic intensity is similar to that of the depth of the top of the engineering bedrock shown in Fig.3, and that of the predominant period shown in Fig.8. 
(a)

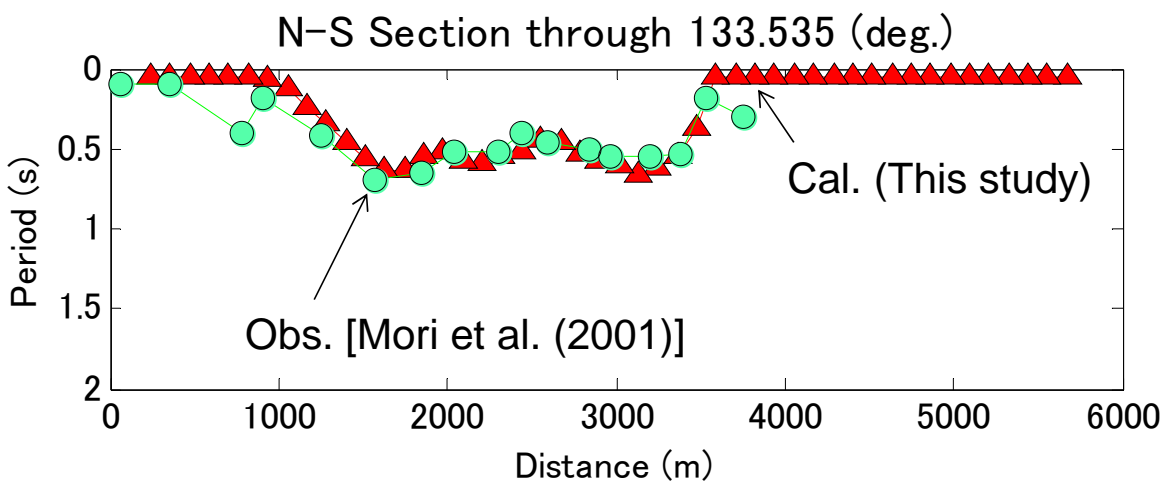

(b)

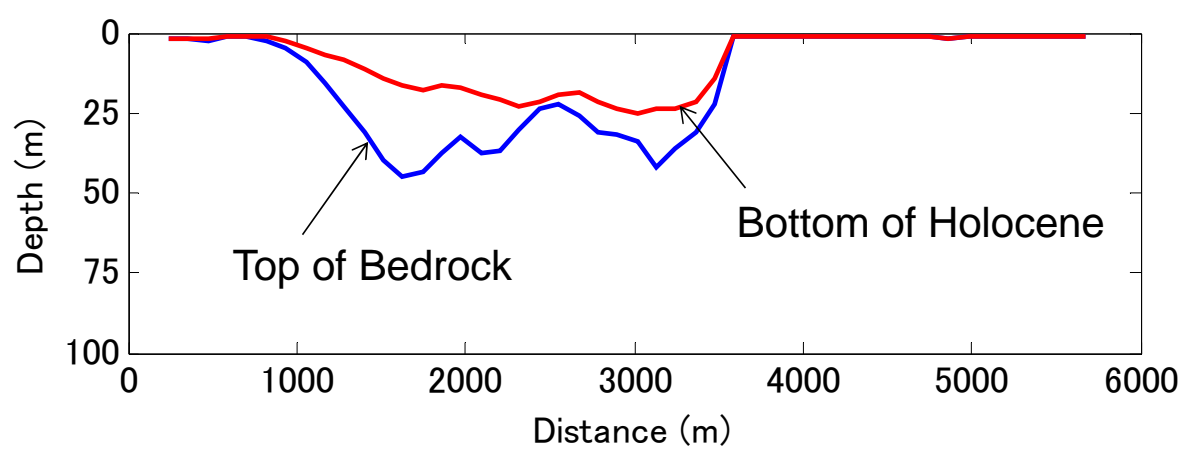

Fig.9 Schematic diagram along a line E-E’. (a) Predominant period, (b) Depth of layers.

(a)

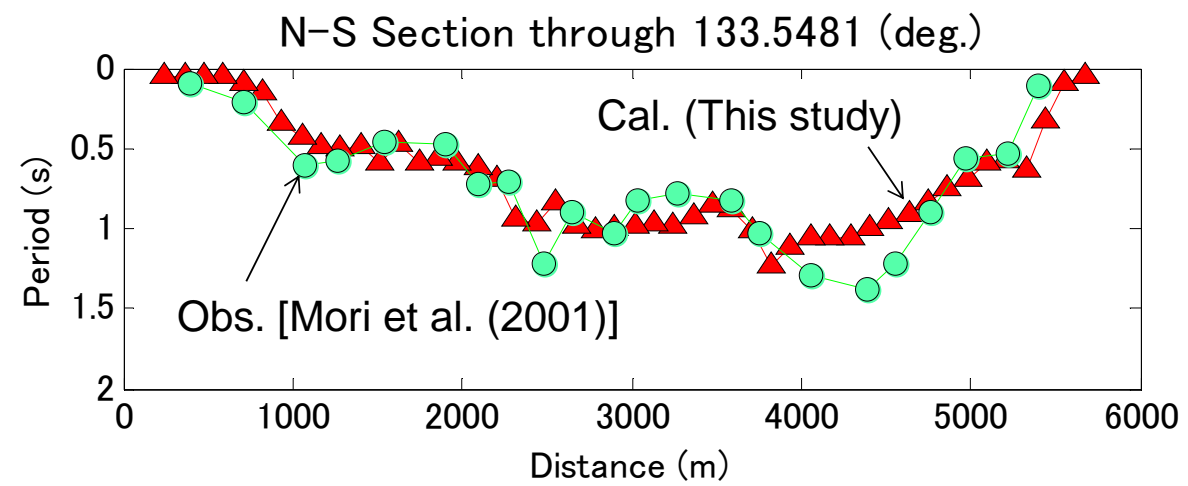

(b)

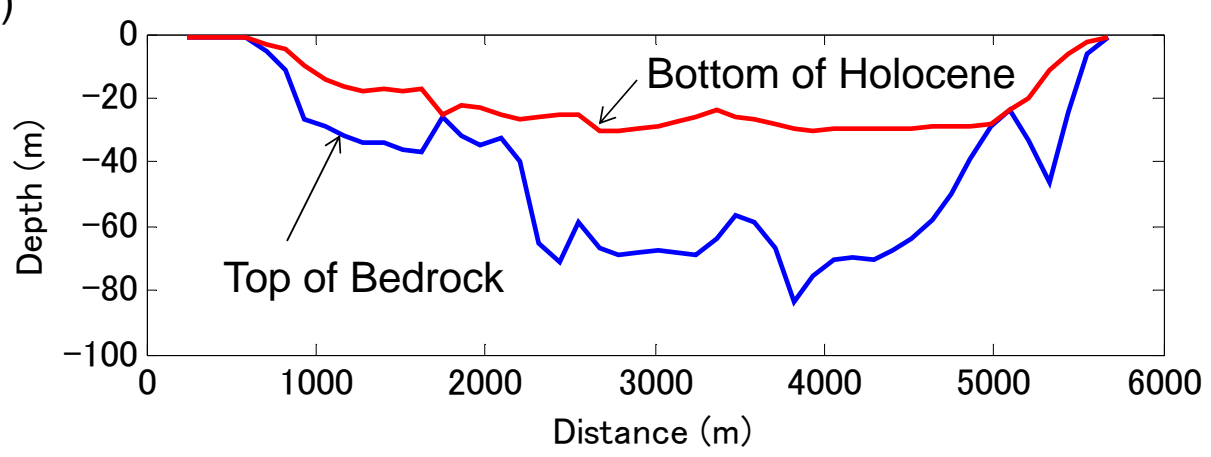

Fig.10 Schematic diagram along a line F-F’. (a) Predominant period, (b) Depth of layers. 


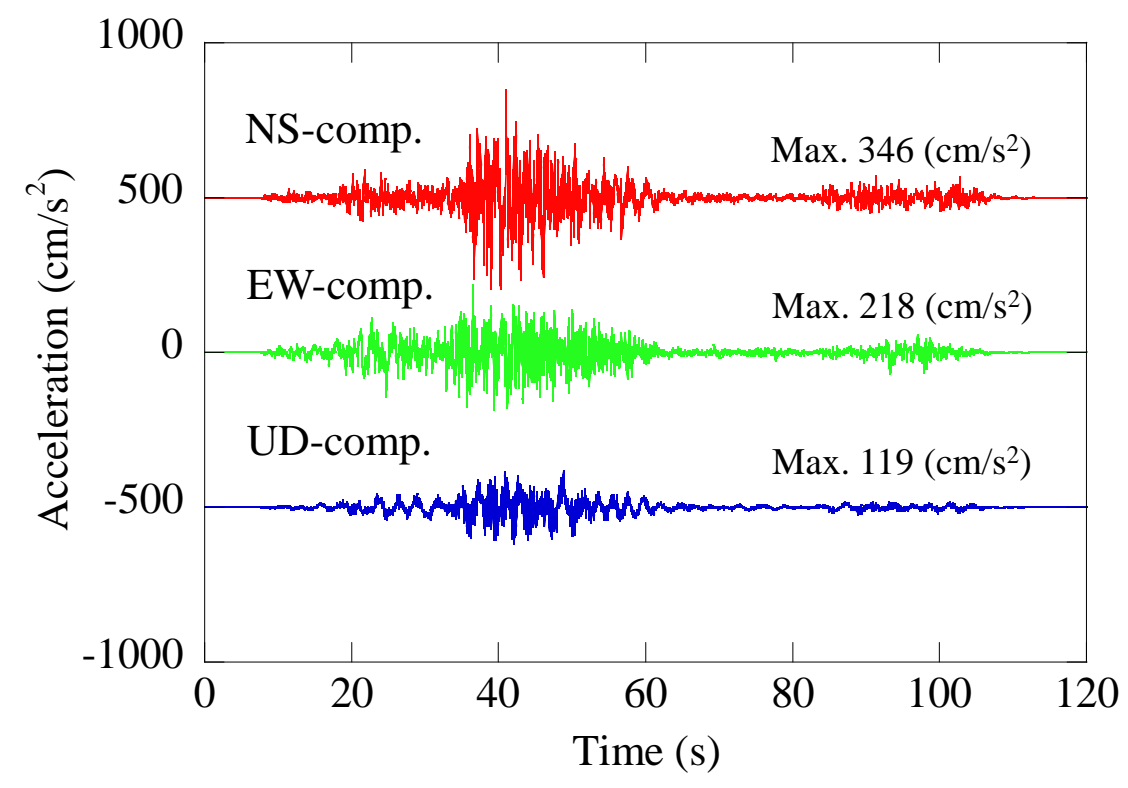

Fig. 11 Acceleration waveforms used as the input motion applied to the engineering bedrock opened by Central Disaster Prevention Council (2003).

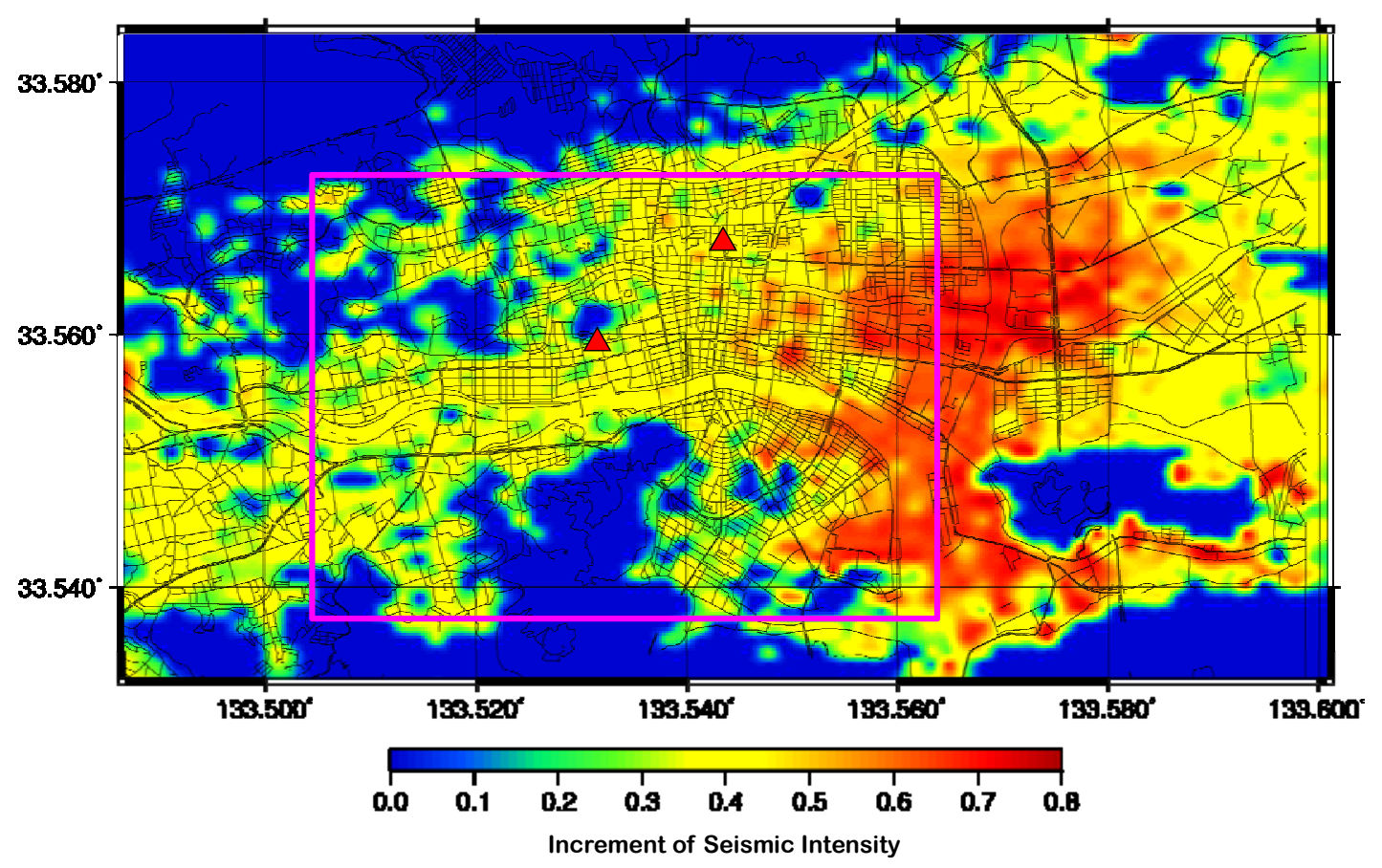

Fig. 12 Map showing the spatial distribution of the increment of the seismic intensity.

We also performed an equivalent linear analysis using the dynamic characteristics of the soil as proposed by the Central Disaster Prevention Council, Japan (2003), and found that the shear strain became $>5 \%$ in the strongly shaken area shown in Fig.12, and reached $>1 \%$, which is considered to 
be the application limit of the equivalent linear analysis. Although we omitted the data in Fig.12, the results obtained using an equivalent linear analysis were $10 \%-20 \%$ lower when employing the modified maximum acceleration, A0, for the seismic intensity (Sekita (1996)) and 0.1-0.2 lower when using increments in the seismic intensity compared with the linear analysis. We note that the spatial distribution using increments in the seismic intensity estimated from the equivalent linear analysis was similar to that shown in Fig.12.

In Fig.13, we show the distribution map of the seismic damage during the 1946 Nankai Earthquake, as investigated by Mashiro (2011). In Fig.13, the area in black denotes the location of low earthquake-resistant wooden houses known as "barracks" that were constructed after World War 2. Mashiro (2011) investigated the ratio of completely destroyed houses reported in "The Great Nankai Earthquake" in the Kochi Prefecture (1949), and distinguished seismic damage from war damage in Kochi City. As can be seen in Fig.13, the seismic intensity was relatively large in the eastern area, and the seismic intensity scale of 7 was concentrated in the area located east of the barracks and the Sambashi-dori areas. Comparing Figures 12 and 13, we can observe that the area with a high increase in seismic intensity estimated using our model agrees well with the area of high seismic intensity felt during the 1946 Nankai Earthquake. A similar tendency was found in the spatial distribution of the seismic intensity observed during the 1854 Nankai Earthquake (Tsuji (2007)).

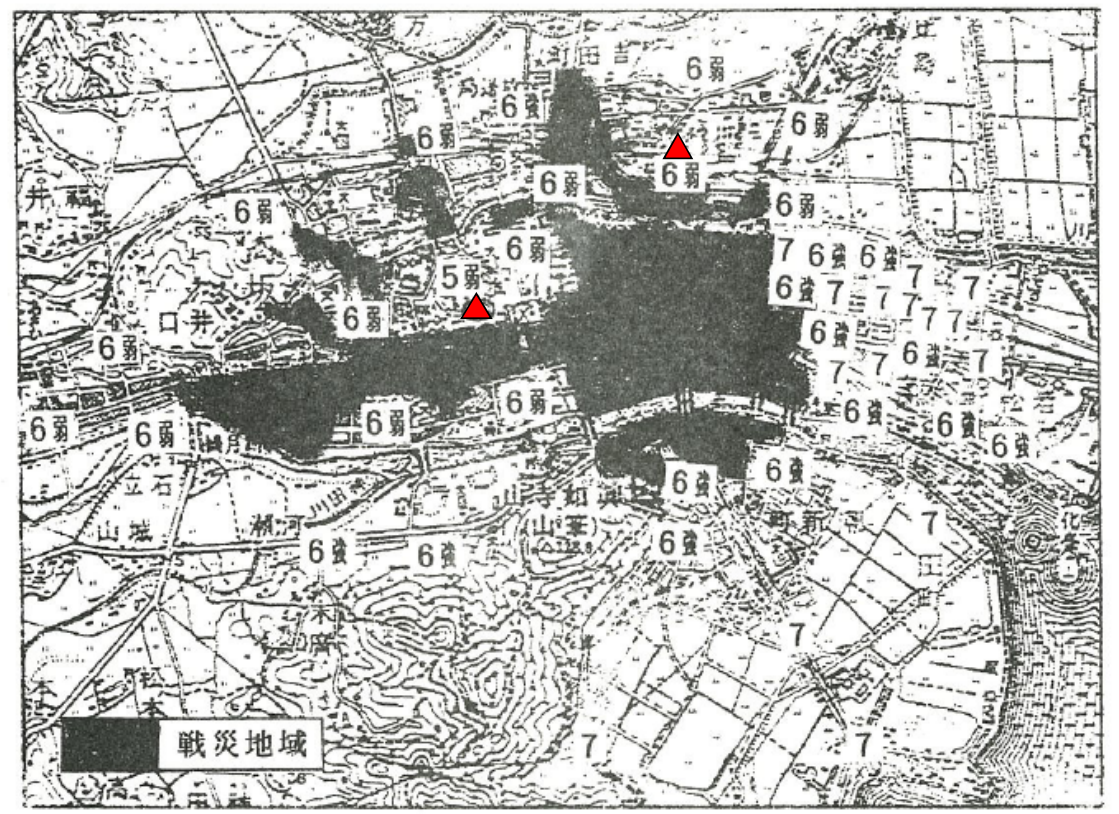

Fig. 13 The distribution map of the seismic damage during the 1946 Nankai Earthquake by Mashiro (2011) with a slight modifcation.

\section{CONCLUSIONS}

In this paper, we constructed a shallow underground structural model of Kochi City for an area 10.5 $\mathrm{km}$ east-west by $5.5 \mathrm{~km}$ south-north with a resolution of $125 \mathrm{~m}$, because Kochi City is of interest as an area where serious damage is expected in the occurrence of a great earthquake along the Nankai Trough. An enhancement of the accuracy of strong motion prediction is an urgent issue for disaster mitigation in Kochi City. By compiling the open geological information from the Committee of Kochi Geo-Hazard Evaluation (2011), we constructed a multilayered model embedded over the engineering bedrock with an S-wave velocity of $700 \mathrm{~m} / \mathrm{s}$. Based on our newly developed model, the dispersion characteristics of theoretical surface waves at two sites were calculated and agreed well with 
observations derived from our microtremor array experiments. The predominant periods along two north-south lines calculated from our model were coincident with previous observational data derived from microtremor H/V spectral ratios by Mori et al. (2001). We also conducted a seismic response analysis using the synthesized ground motion from the Central Disaster Management Council of Japan (2003) as the input motion applied to the basement of the developed subsurface structural model. We found that the area where relatively high seismic intensity was predicted corresponded well with the area that was severely damaged during the 1946 Nankai Earthquake.

\section{ACKNOWLEDGMENT}

Our field measurements in Kochi City would not have been possible without the cooperation of many people working for Kochi Prefecture, Kochi City, the Tosa National Highway Office, and other organizations. We express sincere gratitude to those concerned. In the construction of the shallow subsurface structure, we collected data from, and referred to, numerous geological information sources: bore data, geological models, and geological sections from the Kochi Disaster Information and Sub-structure Evaluation Committee (2011), geological models, predicted waveform data against the 1994 Nankai Earthquake by the Central Disaster Prevention Council, Japan (2003), and to geomorphologic classification by the National Research Institute for Earth Science and Disaster Prevention. To validate the model constructed in our study, we asked Prof. Mori of Ehime University, Japan, if we could digitize the predominant period data from the figure in his article and use it for comparison. We appreciate deeply his kindness. Most of the figures in this paper were drawn using the Generic Mapping Tools (GMT) software package developed by Drs P Wessel and WHF Smith. We respect their superior work and generosity. The manuscript in its original Japanese form was significantly improved after constructive comments from three anonymous reviewers. Our deep

appreciation is given to them. This study was partially supported by Grants-in-Aid for Scientific Research (C) (24540464 \& 25420479).

\section{REFERENCES}

Capon, J. (1969). "High-resolution frequency-wavenumber spectrum analysis”, Proc. IEEE Vol. 57, $1408-1418$.

Central Disaster Prevention Council, Japan (2003). Reference document for Subsurface Structure No. 2-3, 16th Meeting of Tonankai and Nankai Earthquake Investigation Committee. http://www.bousai.go.jp/jishin/chubou/nankai/16/ sankousiryou2_3.pdf. (in Japanese) $<$ last accessed in January 13, 2012>

Editorial Committee for the Ground Diagram of Kochi (1992). The Ground Diagram of Kochi , 461p., 1992. (in Japanese)

Fujiwara, H. (2009). "Development of integrated geophysical and geological information database”, Proc. 3rd Symposium of Integrated Geophysical and Geological Information Database (An Interim Report), 5-14. (in Japanese)

Geospatial Information Authority of Japan (2008). "Digital elevation model with a resolution of $5 \mathrm{~m}$ in Kochi”, CD-ROM.

Hasegawa, S., Yatabe, R., Mochizuki, A., Nishiyama, K., and Yamamoto, K. (2009). "Development of the Shikoku Geo-Informatics Database and extracted profile of alluvial plains”, 50th Anniversary Publication of Shikoku Branch, The Japanese Geotechnical Society, 91-126. (in Japanese)

Headquarters for Earthquake Research Promotion (2012). Overview of long-term evaluation of subduction earthquakes, http://www.jishin.go.jp/main/choukihyoka/ichiran.pdf. (in Japanese) $<$ last accessed in January 13, 2012>

Hiroi, H., Okazaki, H., Nakata, S., and Arai, H. (2010), "Seismic bedrock structure under Kochi plain estimated from microtremor conventional measurements”, Proc. 45th Japan National Conference 
on Geotechnical Engineering, 1853-1854. (in Japanese)

Katto, J. and Nishi, K. (1971), "Geomorphology and subsurface geology of the alluvial plain of Kochi, Shikoku, West Japan”, Research Reports of Kochi University, Natural Science, Vol. 20, No. 13, 219-239. (in Japanese)

Katto, J. and Nishi, K. (1972), "Geomorphology and subsurface geology of the alluvial plain of Kochi, Shikoku, West Japan”, Journal of Geological Society of Japan, Vol. 7, 137-143. (in Japanese)

Kochi Disaster Information and Sub-structure Evaluation Committee (2011). Kochi City Disaster and Sub-Structure Related Information, http://www.geonews.jp/kochi/index.html. (in Japanese) $<$ last accessed in May 31, 2011>

Kochi Prefecture (1949). The Great Nankai Earthquake, 692p. (in Japanese)

Kochi Prefecture (2004). Secondary Basic Research for Measures against Earthquake in Kochi Prefecture. (in Japanese)

Mashiro, T. (2011). The Nankai Earthquake, 91p., Asahi-Toshado. (in Japanese)

Ministry of Education, Culture, Sports, Science and Technology, Japan. Special Project for Earthquake Disaster Mitigation in Urban Areas (2002-2006), http://www.mext.go.jp/a_menu/kaihatu/jishin/04031203.htm. (in Japanese) <last accessed in January 13, 2012>

Ministry of Education, Culture, Sports, Science and Technology, Japan. Research for the Tonankai and Nankai Earthquakes (2003-2007),

http://www.mext.go.jp/a_menu/kaihatu/jishin/04031204.htm. (in Japanese) <last accessed in January 13, 2012>

Ministry of Education, Culture, Sports, Science and Technology, Japan. The Project for Seismic Linkage for Tokai, Tonankai and Nankai Earthquakes (2008-2012). , http://www.mext.go.jp/b_menu/houdou/20/04/08040308.htm. (in Japanese) <last accessed in January 13, 2012>

Ministry of Land, Infrastructure, Transport and Tourism (2008). Draft Standard Procedure for Electric Delivery of Geological and Soil Survey Outcome. http://www.banno.co.jp/cals-guide/standard/sc06b.pdf . (in Japanese) <last accessed in January 13, 2012>

Miyakoshi, K. Personal Communication.

Mori, S., Mori, N., Tawara, T., and Okamoto, K. (2001). "Predominant period microtremor measurement," Proc. 36th Japan National Conference on Geotechnical Engineering, 2335-2336. (in Japanese)

National Research Institute for Earth Science and Disaster Prevention, “Japan Seismic Hazard Information Station”, http://www.j-shis.bosai.go.jp/. <last accessed in June 4, 2009>

Ohori, M., Nobata, A. and Wakamatsu, K. (2002). "A Comparison of ESAC and FK methods of estimating Phase Velocity using Arbitrarily Shaped Microtremor Arrays”, Bull. Seism. Soc. Am., Vol.92, 2323-2332.

Okada, H. (1994). "A research on the practical application of microtremor exploration technique to a wide area survey of a underground structure under 3,000 $\mathrm{m}$ in depth”, Report of a Grant-in-Aid for Co-operative Research (B) No. 03554009 supported by the Scientific Research Fund in 1993. (in Japanese).

Saito, A. and Hasegawa, S. (2007), "Seismic characteristics of Kochi pain estimated from microtremor measurements”, Proc. 13th Meeting of Shikoku Branch, Japan Society of Civil Engineers, 224-225, 2007. (in Japanese)

Saito, M. (2007). "Separation of longitudinal and transversal components in microtremors by using a horizontal component seismic array”, Butsuri-Tansa, Vol. 60, 297-304. (in Japanese)

Sekita, Y. (1996). "Revised Seismic Intensity Scale of Japan Meteorological Agency”, Japan Society for Earthquake Engineering Promotion News, Association for Earthquake Disaster Prevention, No.147, 21-26. (in Japanese)

Shikoku Geo-Informatics Council (2005). Shikoku Geo-Informatics Database, CD-ROM.

Tokimatsu, K. Arai, H., and Sakai, J. (1995). "Characteristics of surface waves in short-period microtremor and their relation to shear-wave structures", J. Struct. Constr. Eng., Architectural 
Institute of Japan, No.472, 47-55. (in Japanese)

Tsuji, Y. (2003). Disaster Research Forum 2002 Lecture "Great Earthquake Disaster Scenarios, Tokai, Tonankai and Nankai earthquake -What happens at that time-", Lessons learnt from earthquake disasters scenario from past Tokai, Nankai Earthquakes, Non-Life Infrastructure Rating Organization of Japan, Earthquake Insurance Research, Vol. 2, 21-31, 71-76. (in Japanese)

Tsuji, Y. (2007). "Detailed Seismic Intensity around Kochi Castle (Part 2)”, A Series of Articles about Historical Earthquakes, No.94, The Kochi Shimbun. (in Japanese)

Uebayashi, H. (2003). "Extrapolation of irregular subsurface structures using the horizontal-to-vertical spectral ratio of long-period microtremors”, Bull. Seism. Soc. Am., Vol. 93, 570-582.

Wessel, P. and Smith, W.H.F. (1990). "Gridding with continuous curvature splines in tension", Geophysics, Vol.55, pp.293-305.

Wessel, P. and Smith, W.H.F. (1999). The Generic Mapping Tools Technical Reference and Cookbook, Version 3.3, 132.

Yatabe, R., Kawashima, S., Yamamoto, K., Nakamura, K., Hirota, K., and Kira.T. (2008).

"Subsurface ground profile of Kochi plain extracted with the Shikoku Geo-Informatics Database", Proc. 43th Japan National Conference on Geotechnical Engineering, 53-54. (in Japanese)

(Original Japanese Paper Published: February, 2013)

(English Version Submitted: March 31, 2015)

(English Version Accepted: April 9, 2015) 